\title{
Primate Self-Medication, Passive Prevention and Active Treatment - A Brief Review
}

\author{
Michael A Huffman
}

Section of Social Systems Evolution, Primate Research Institute, Kyoto University, Japan

\begin{abstract}
Parasites and pathogens are a source of diseases that can affect the health, behavior and reproductive fitness of an individual. The study of animal self-medication as a science is relatively new, but traditional societies have long looked to animals for clues to nature's medicine cabinet. Evidence of self-medication is widespread throughout the animal kingdom. To date, research has classified health maintenance and self-medicative behaviors into five levels: 1) 'sick behaviors'; 2) behavioral avoidance or reduction of the possibility for disease transmission; 3) dietary selection of items with a preventative or health maintenance effect; 4) ingestion of a substance for the curative treatment of a disease or the symptoms thereof, and; 5) application of a substance to the body or a living space for the treatment or control of vectors or external health condition. Among the groups of animals studied to date, primates have provided the most details for level 3 and 4 behaviors, exemplified by such diverse dietary selection and behaviors as bitter pith chewing and whole leaf swallowing behaviors, used directly in response to increased levels of parasite infection.
\end{abstract}

KEYWORDS: Animal self-medication, primates, medicinal plants, disease control, homeostasis

Corresponding author: Michael A. Huffman, Email: huffman@pri.kyoto-u.ac.jp 
"The adaptive value of warding off predators, whether larger and faster, or smaller and stealthier then oneself should not be surprising, yet science has been slow to recognize the ability of animals to avoid, suppress or eliminate parasites and other agents of disease that equally compromise their health and wellbeing. While it appears that an awareness of and even practical applications based on the behavior of animals as a source of medicinal wisdom has been around for much of our own species history, science has been slow to appreciate this." Huffman 2015a

\section{INTRODUCTION}

The study of animal self-medication as a science is relatively recent, although history tells us that humans have traditionally long looked to animals as a source of medicinal knowledge (Engel, 2002; Huffman, 2002; 2007a). Not only have humans learned from watching sick wild animals, because we share the same evolutionary history, possess a common physiology and have lived together under similar environmental condition for much of our species history, it can be argued that we have inherited many of the same ways to combat common diseases in the environment (Huffman, 2015a). In support of this notion, recent archeological and biochemical evidence suggests that a close extinct relative in our lineage, Homo neanderthalensis, also used medicinal plants that are still in use today by our own species (Hardy et al., 2012; 2013; Huffman, 2016).

Research in the field of self-medication is devoted to understanding how animals respond to threats to their health and how these behaviors are transmitted across generations. It has provided a "bio-rational" for the exploration and exploitation of novel secondary plant compounds and new insights into how they can be used for the management of health in humans and livestock (Huffman et al., 1996; 1998; Krief et al., 2005; 2006; Petroni et al., 2016). At the proximate level, self-medication may be driven by the individual's 'need' to maintain physiological homeostasis; that is to feel well (Foitova et al., 2009; Forbey et al., 2009).

To date, the majority of evidence for selfmedication in animals is about ways in which they deal with parasite or pathogen induced illness, but there is no reason why it should be restricted to such illnesses alone (Huffman, 1997; 2007b). As all animals experience illness, it should come as no surprise if we find evidence in virtually every living species today. The ability of a species to defend itself against lifethreatening disease provides a significant adaptive advantage and is predicted to occur throughout the animal kingdom.

Much work exists describing the diversity of host-parasite relationships in the animal kingdom (Clayton \& Moore, 1997). Some parasitic infections seem to go unnoticed by the hosts. In other cases, when homeostasis is disrupted or threatened, it is in the best interest of the host to actively respond to alleviate discomfort. Regardless of the illness, there are four basic requirements for demonstrating selfmedication: i) identify the disease or symptom(s) being treated; ii) distinguish the use of a therapeutic agent from that of everyday food items and or 'medicinal foods'; iii) demonstrate a positive change in health condition following self-medicative behavior, and; iv) provide evidence for plant activity and or direct pharmacological analysis of compounds extracted from these therapeutic agents (Huffman, 1997).

Given our current level of understanding, response to illness, either as health maintenance or direct self-medicative behavior, can be classified into five levels (Huffman, 1994; 2004): 1) 'sick behaviors' (lethargy, depression, anorexia, reduction in grooming, behavioral fever, basking behavior; 2) behavioral avoidance or reduction of the possibility for disease transmission (avoidance of feces contaminated food, water, substrates); 3) dietary selection of items with a preventative or health 
maintenance effect (items eaten routinely in small amounts or on a limited basis); 4) ingestion of a substance for the curative treatment of a disease or the symptoms thereof (use of toxic or biologically active items at low frequency or in small amounts, having little no nutritional value), and; 5) application of a substance to the body or a living space for the treatment or control of vectors or external health condition.

Behaviors to be focused on here fall within levels 3 and 4. In general terms, level 3 includes passive dietary prophylaxis or the consumption of 'medicinal foods' as health maintenance behavior. Emphasis is put on the passive nature of such behavior, since prophylactic treatment implies intentionality and an understanding of both the cause and prevention of illness. So far, this has not been demonstrated in animals, so these dietary choices are expected to be based on some immediate feedback.

Level 4 includes therapeutic behaviors such as the extraction and ingestion of pharmacologically active substances from plants or the peculiar ingestion of plants without nutritional gain. This necessarily requires some level of awareness of wellness and discomfort and the ability to respond with behaviors that bring about positive change in one's condition.

Evidence for self-medication at these two levels has been found across the animal kingdom, with homologous behaviors appearing in phylogenetically distant taxa (e.g. swallowing of whole leaves for the expulsion of tapeworms and nodule worms in chimpanzees, gorillas, bonobos, gibbons, and brown bear, snow geese, civets Huffman, 1997; also see below). The diversity of potentially self-medicating species recognized thus far reflects the common need to prevent, suppress or cure disease, as mentioned above. Current evidence suggest that for insects, self-medication may be operated entirely by innate mechanisms (Bernays \& Singer, 2005), while for some higher vertebrates like chimpanzees, important aspects of selfmedication, such as what plant species and when and how to ingest it, appear to be acquired and transmitted from generation to generation via socially biased learning and maintained in the group as culture (Huffman \& Hirata, 2004; Huffman et al., 2010).

\section{DIETARY SELECTION OR PASSIVE DISEASE PREVENTION?}

\subsection{Medicinal food}

For energy, growth, general maintenance, and reproduction the selection a proper diet is very important. Typically one thinks of animal feeding strategies as being based on finding and consuming the most essential nutritional elements that is carbohydrates, fats, proteins and vitamins and while at the same time avoiding the negative impact of secondary metabolites in plants. For plants, these secondary metabolites protect them from over predation from an array of herbivores (insect, vertebrates) that prey upon them by reducing palatability and / or digestibility (Glander, 1982). Nonetheless, this does not necessarily prevent some animals from actually benefiting from these defense compounds. Adult danaine butterflies store bitter and toxic pyrrolizidine alkaloids in their bodies for defense against predators and males depend on them as a precursor for the biosynthesis of a pheromone component needed for courtship. The wooly bear caterpillars of the tiger moth (Platyprepia virginalis) protect themselves from the fatal effects of tachinid parasitoid wasp larvae (Thelaira americana) infection by changing their diet from innocuous lupine (Lupinus arboreus) to the toxic alkaloid abundant hemlock (Conium maculatum) if they become infected. The alkaloids may not kill the developing parasite within the caterpillar, but it does allow the caterpillar to survive such an infection. Studying these kinds of tri-trophic interactions (insect host, plant, parasite) can surely help to better understand the foundations for the evolution of self-medication in higher vertebrates (Bernays \& Singer, 2005). 
In 1997, I introduced the concept of medicinal foods to primatology, adding an extra element of passive disease prevention based on the presence of plants in the diet that containing noticeable bioactive properties. This term was borrowed from the human ethnopharmacological literature (Etkin, 1996). For example, among the Hausa peoples of Nigeria, $30 \%$ of the wild plant food species are also used as medicine. Interestingly, $89 \%$ of the species used by these people to treat symptoms of malaria are also used in a dietary context (Etkin \& Ross, 1983). Many food items eaten by primates and other mammals also contain a variety of secondary metabolites with medicinal properties (roughly 15 25\% of any populations food plant species list), suggesting that animals may benefit from the periodic ingestion, in small amounts, of these plants (Huffman, 1997; Huffman \& MacIntosh, 2012; Krief et al., 2006; MacIntosh \& Huffman, 2010; Mukherjee et al., 2011).

\subsection{Nutrient poor items}

Some other interesting items are found in the diets of many primate species. Bark and wood are by nature highly fibrous, heavily lignified, sometimes toxic, relatively indigestible and nutrient poor. While the list of plant species whose bark is ingested by primates is long, little is actually known about their contribution to the diet and general health (Huffman, 1997). Sodium has been suggested to be the reason why gorillas in the Impenetrable Forest and chimpanzees in the Budongo Forest of Uganda to consume large quantities of dead wood (Reynolds et al., 2009; Rothman et al., 2006). At Mahale in Tanzania, chimpanzees also infrequently ingest the bark and wood of several plant species.

The bark of Pycnanthus angolensis (Welw.) Warb. (Myristicaceae) ingested by chimpanzees at Mahale is used by West Africans as a purgative, laxative, digestive tonic, emetic and reliever of toothaches. Chimpanzees at Gombe in western Tanzania occasionally eat the bark of
Entada abyssinica (Mimosaceae). In Ghana, the bark is used for diarrhea and as an emetic. The bark of Gongronema latifolium (Asclepiadaceae) occasionally eaten by chimpanzees at Bossou in Guinea, is extremely bitter, and the stems are used by some West Africans as a purge for colic, stomach pains and symptoms connected with intestinal parasite infection (Huffman, 1997).

\subsection{Hallucinogens and stimulants}

Stories of insects, birds and mammals under the influence of fermented fruit or other plant material are widespread in wildlife lore and literature around the world, but few examples have been documented scientifically. One example from Africa stands out and is perhaps the best scientifically documented hallucinogen ingested by animals. The plant is Tabernanthe iboga, (Apocynaceae), a shrub first described in 1889 (Dubois, 1955; Harrison, 1968).

Today, T. iboga is still used in religious rituals in Cameroon. Indigenous forest hunter gatherers reportedly discovered the hallucinogenic properties of this plant by watching gorillas, wild boars and porcupines digging up and eating the roots, afterwards going into a wild frenzy, running about as if being chased by some frightening animal.

The hallucinogenic affect of this plant was demonstrated in the early 1900's and later replicated in the 1950's by pharmacological tests carried out on animals in the laboratory. More recently, the plant was under investigation in the US as an alternative for methadone, a standard treatment for drug addicts (Dubois, 1955; Harrison, 1968).

A complete review of the gorilla diet literature uncovered many well-known medicinal plants with well-documented stimulatory, cardiotonic and hallucinogenic properties (Cousins \& Huffman, 2002). Gorillas utilize many species of Kola (Cola) (Sterculiaceae) particularly for their seeds, including Cola nitida, $C$. 
pachycarpa and C. rostrata. The seeds of $C$. pachycarpa contain such natural products as caffeine and theobromine. The amino acid content in the nuts of Kola suggests weak protein levels, which suggests that gorillas obtain primarily caffeine from the fruits and seeds (Cousins \& Huffman, 2002).

Mountain gorillas living in the Virunga volcano range travel periodically to the upper slopes around 1,100-3,200 meters above sea level. At these heights, they feed on species of giant Lobelia (Campanlaceae) and Senecio (Compositae), both of which are important plants in ethnomedicine.

All members of the genus Lobelia contain alkaloids (iobeline, iobelanidine and norlobelanidine), which have a long lasting stimulatory effect of up to 15 minutes when ingested. Higher doses can have narcotic effects. Indigenous peoples of the New World use many species of Lobelia as treatment and inebriates. Gorillas reportedly feed on $L$. giberroa and L. wallastonii only occasionally (Cousins \& Huffman, 2002).

\subsection{Antibiotic properties}

Many primates feed on figs and many Ficus spp. are known to contain anti-parasitic activity. Clinical trials on both humans and non-human animals have shown that preparations of some fig species are effective against nematodes such as Ascaris and Trichuris. Ficin, a proteolytic enzyme is present in all fig trees, and is known to be an active ingredient. Even a low concentrations of around $0.05 \%$ of Ficus glabrata latex has been shown to destroy the cuticle of Ascarid helminths and cause related lethal changes to the parasite's body (Huffman, 1997).

Pith and fruit of species of the wild ginger (Afromomum) are frequently eaten by primates. From the literature on Afromomum species eaten by gorillas, significant bactericidal activities against Escheria coli, Pseudomonas aeruginosa,
Yersinia entercolitica, Bacillus subtilis, Proteus vulgaris, Klebsiella pneumoniae and Serratia marcescens. Fungicidal activities inhibited Candida albicans, Trichophyton mentagrophytes, Aspergillus niger, Botryodiplodis theobromae and species of Cladasporium cladosporiodes were found (Huffman, 1997).

Timothy Jones argues that the herbal medicines and modern pharmaceuticals used by today have replaced the non-nutritive chemicals typically present in the diets of animals in the wild (Johns, 1990). As governments in the industrial world come to realize the economic benefits and conventional wisdom of investing in disease prevention, a growing market has begun to develop, to promote health through dietary supplements (nutriceuticals).

\section{THERAPEUTIC SELF MEDICATIVE BEHAVIOR}

\subsection{Ape self-medication}

Two forms of therapeutic behavior have received the most attention in the field of animal self-medication. They are bitter pith chewing and leaf swallowing. To date, among primates the two parasites associated with both bitter pith chewing and leaf swallowing are the nodular worm (Oesophagostomum stephanastomum; Figure 1) and the tapeworm (Bertiella studeri). The nodular worm is perhaps one of the most hazardous species found in the great apes (Huffman, 1997).

Repeated infection, which is quite common in the wild, causes significant complications including secondary bacterial infection, diarrhea, severe abdominal pain, weight loss, and weakness, which can result in death.

The deleterious affects of the tapeworm are not well documented, but abdominal pain is presumed to be associated with heavy infections (Huffman, 1997). 


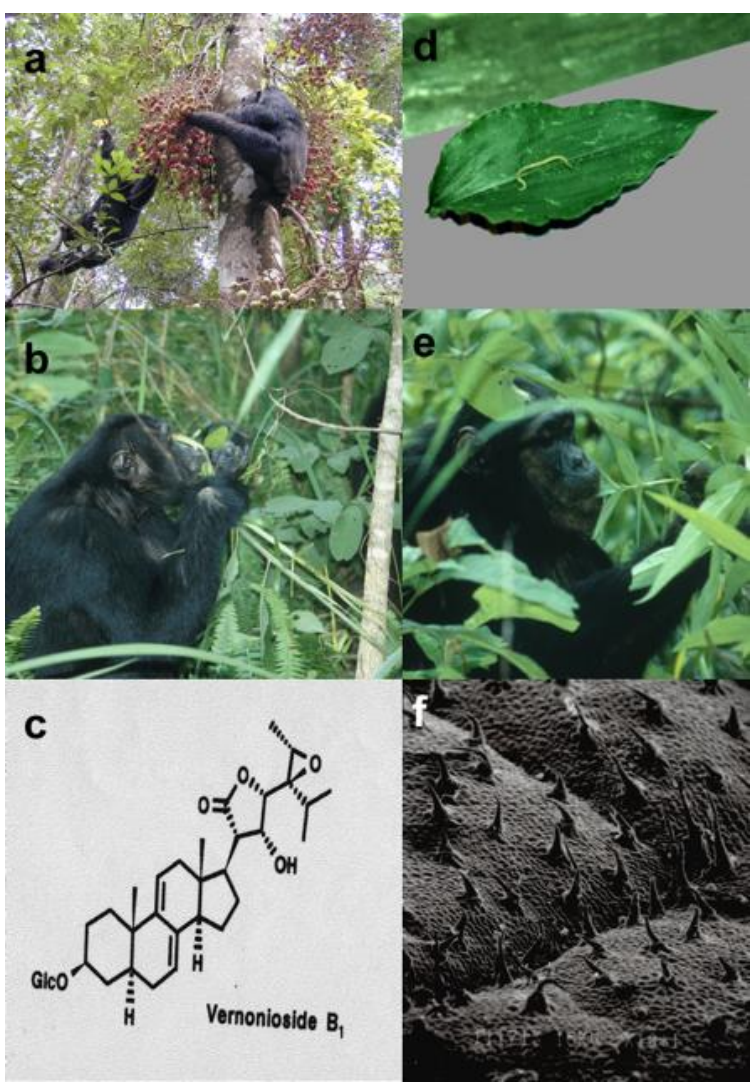

Figure 1. Chimpanzee self-medication. a). chimpanzees feeding on figs in the Mahale Mountains National Park, Tanzania., b). adult male chewing on bitter pith of Vernonia amygdalina, $\mathrm{c}$ ). vernonioside $\mathrm{B} 1$, most bioactive of the vernoniosides isolated from $V$. amygdalina pith, d). adult worm of Oesophogostomum stephanostomum and Anilema acquinoctial, a species of leaf swallowed whole by African apes, e). adult male swallowing the leaves of Aspilia mossambicensis, f). SEM image of the surface of Lippia plicata, a species swallowed whole by chimpanzees.

\subsection{Bitter Pith Chewing}

Bitter pith chewing is proposed to aid in the control of nodule worm infection, via pharmacological action, and relief from gastrointestinal upset. The hypothesis that bitter pith chewing has medicinal value for chimpanzees was first proposed from detailed behavioral observations, and parasitological and phytochemical analyses of patently ill chimpanzees ingesting Vernonia amygdalina (Compositae), and recovering from their symptoms within 20 hours (Huffman \& Seifu, 1989; Huffman et al., 1993).

Inside Mahale M group's home range, where this behavior was first documented, $V$. amygdalina is neither abundant nor evenly distributed throughout their territory (Huffman $\&$ Seifu, 1998). Use by chimpanzees of this plant often requires a detour from the group's commonly used travel routes. When ingesting the pith from younger fleshy shoots of $V$. amygdalina, chimpanzees carefully remove the bark and leaves, then chew on the inner pith, extracting only the extremely bitter juice and only small amounts of fiber (Figure 1). The amount of pith taken at one time is insignificant from a nutritional perspective; portions ranging from 5 to $120 \mathrm{~cm} \mathrm{X} 1 \mathrm{~cm}$. Altogether, depending on the number of leaves ingested, this act takes anywhere from less than 1 to 8 minutes, and bitter pith chewing appears to be a one-dose treatment. Individuals have not been seen to chew bitter pith again within the same day or even within the same week. This might possibly be due to the plant's toxicity. Adult chimpanzees in proximity to a sick individual chewing Vernonia bitter pith very rarely show interest in ingesting the pith themselves. On the other hand, infants of ill mothers are known to taste small amounts of the pith discarded by their mothers. Despite a year round availability of the plant, use of this pith by chimpanzees is highly seasonal and rare, occurring most frequently during the rainy season peak in nodule worm infections - as expected for a therapeutic treatment (Huffman \& Seifu, 1998; Huffman et al., 1993).

A noticeable drop in appetite, malaise, diarrhea or constipation and high levels of nodule worm infection characterized the condition of the individuals observed engaging in bitter pith chewing. Marked recovery from these symptoms occured within 20-24 hr after pith chewing. In one case, the nodular worm eggs 
per gram feces level (EPG, a relative measure of the intensity of an infection) were measured and found to have dropped from an EPG count of 130 to 15 within 20 hours (Huffman et al., 1993).

Ethnic groups across Africa prepare a concoction made from $V$. amygdalina leaves or bark, and prescribe treatment for malarial fever, schistosomiasis, amoebic dysentery, several other intestinal parasites and stomachaches (Huffman et al., 1996). The above noted recovery time of 20-24 hours after bitter-pith chewing in two $M$ group chimpanzees is comparable to that of local human inhabitants of this region, the WaTongwe, who use cold water concoctions of the leaves as a treatment for parasites, diarrhea and stomach upset (Huffman \& Seifu, 1989).

Also phytochemical analysis back in the laboratory revealed the presence of two major classes of bioactive compounds; 4 sesquiterpene lactones and 7 new stigmastane-type steroid glucosides, and 2 freely occurring aglycones of these glucosides (Ohigashi et al., 1994).

The sesquiterpene lactones are well known for their anthelmintic, antiamoebic, antitumor, and antibiotic properties. From crude methanol extracts of the leaves, inhibition of tumor promotion and immunosuppressive activities have also been identified. In vitro tests on the antischistosomal activity of the pith's most abundant steroid glucoside (vernonioside B1; Figure 1) and sesquiterpene lactone (vernodaline) showed significant inhibition of movement of all adult stage parasites and of adult females' egg-laying capacity (Ohigashi et al., 1994).

Together, the evidence gathered from research at Mahale derived from behavioral, parasitological, pharmacological and ethnomedicinal studies lend strong support to the hypothesis that bitter pith chewing is a therapeutic form of self-medication stimulated by, and controlling parasite infection.

\subsection{Leaf-swallowing}

Leaf-swallowing behavior in the African great apes was first reported for chimpanzees at Gombe and Mahale by Richard Wrangham and Toshida Nishida (Huffman, 2015b). It came to their attention that leaf-swallowing was unlikely to provide any nutritional value after they found the folded, whole and undigested leaves of Aspilia mossambicensis (Compositae), $A$. pluriseta, and $A$. rudis in the feces of chimpanzees. The interest generated in this behavior stimulated many field researchers to look for leaf swallowing at their ape study sites.

To date, leaf-swallowing has been observed in multiple populations of chimpanzee (Pan troglodytes schweinfurthii, P.t. troglodytes, P.t.verus), bonobo ( $P$. paniscus) and eastern lowland gorilla (Gorilla gorilla graueri) across Africa (Figure 2). Very recently the behavior has also been reported for the first time in an Asian ape species, the white-handed gibbons (Hylobates lar) in Khao Yai National Park, Thailand (Barelli \& Huffman, 2016). In all plant species used by these African and Asian apes, the leaf surface shares the common property of being rough-surfaced, covered in stiff hairs or trichomes (Figure 1). These abrasive hairs are made of silicates that are difficult to digest; a defense strategy of plants to inhibit over eating by herbivores.



Figure 2. Study sites across Africa where apes are currently known to self-medicate with either bitter pith chewing and or whole leaf swallowing. 
Leaf-swallowing has been shown to reduce nodule worm infection, and possibly relieve pain caused by tapeworm infection, by expelling these two intestinal parasite species from chimpanzees (Huffman \& Caton, 2001). The demonstrated mode of parasite infection control is a physical mechanism that expels parasites by a self-induced increase in gut motility that acts as a purge. The behavior is easy to distinguish from normal consumption of leafy material. The distal half of a leaf is selected one at a time, folded by tongue and palate while slowly pulling it into the mouth. Each leaf is individually swallowed whole without chewing (Figure 1). The leaves' roughness makes them difficult to swallow, so folding them with the tongue and palate before swallowing is a necessary part of ingestion, and is responsible for their exiting totally undigested.

At one sitting taking from one to 15 minutes or more, an individual can swallow anywhere from 1 to 100 leaves. Unlike bitter pith chewing, an individual may swallow leaves more than once in a day and over several consecutive days. Chimpanzees will often swallow leaves within the first few hours after leaving their sleeping nests before the first meal and or on a relatively empty stomach. This timing is thought to be most important for the behavior to be effective (Huffman \& Caton, 2001). At Mahale, Gombe, Kibale, Lomako (DR Congo) and Fongoli (Senegal) where longitudinal studies have now been conducted, leaf swallowing is shown to occur widely across the distribution of African great apes (Figure 1).

\section{THE FUTURE}

Much remains to be learned about the selfmedicative behavior of animals, as there are still so many species unexplored, but as shown above, reoccurring patterns of the type of behavior and the kinds of parasites associated with them emerge. With time and diligent research I think the future will bring us many new discoveries. We stand to gain not only knowledge about future medicines for humankind, but have the chance to use this knowledge to convince others that the natural world is worth preserving, and the creatures that we share this planet with have much knowledge to yet to share with us and must be allowed to live their lives in peace.

Sabbe Satta Bhavantu Sukhitatta.

\section{REFERNCES}

BARELLI C \& HUFFMAN MA. Leaf swallowing and parasite expulsion in Khao Yai white-handed gibbons (Hylobates lar), the first report in an Asian ape species. American Journal of Primatology. 2016; doi: 10.1002/ajp.22610

BERNAYS EA \& SINGER MS. Taste alteration and endoparasites. Nature. 2016; 436: 476.

CLAYTON DH \& MOORE J. Host-Parasite evolution. General Principles \& Avian Models. Oxford University Press, Oxford. 1997.

COUSINS D \& HUFFMAN MA. Medicinal properties in the diet of gorillas- an ethnopharmacological evaluation. African Studies Monographs. 2002; 23: 65-89.

DUBOIS L. Tabernanthe iboga Baillon. Bulletin Agricole du. Congo Belgique. 1955; 46: 805829.

ENGEL C. Wild Health. Boston: Houghton Mifflin Company. 2002.

ETKIN NL. Medicinal cuisines: diet and ethnopharmacology. International Journal of Pharmacognosy. 1996; 34 (5): 313-326.

ETKIN NL \& ROSS PJ. Malaria, medicine, and meals: Plant use among the Hausa and its impact on disease. In L. Romanucci-Ross, D. E. Moerman, \& L. R. Tancredi (Eds.), The anthropology of medicine: From culture to method. New York: Praeger. 1983; 231-259. 
FOITOVA I, HUFFMAN MA, WISNU N \& OLŠANSKÝ M. Parasites and their Effect on Orangutan Health. In S.A. Wish, S.S. Utami, T.M. Setia \& C.P. van Schaik (eds.). Orangutans - ecology, evolution, behavior and conservation. Oxford University Press. 2009; 157-169.

FORBEY J, HARVEY A, HUFFMAN MA, PROVENZA F, SULLIVAN R \& TASDEMIR D. Exploitation of secondary metabolites by animals: A behavioral response to homeostatic challenges. Integrative and Comparative Biology. 2009; 49(3): 314-328.

GLANDER KE. The impact of plant secondary compounds on primate feeding behavior. Yearbook of Physical Anthropology. 1982; 25:118.

HARDY K, BUCKLEY S, COLLINS MJ, ESTALRRICH A, BROTHWELL D, COPELAND L, GARC'IA-TABERNERO A, GARC'IA-VARGAS S, DELA RASILLA M, LALUEZA-FOX C, HUGUET R, BASTIR M, SANTAMAR'IA D, MADELLA M, FERN'ANDEZ CORT'ES A \& ROSAS A. Neanderthal medics? Evidence for food, cooking and medicinal plants entrapped in dental calculus. Naturwissenschaften. 2012; 99: 617-26. doi:org/10.1007/s00114-012-0942-0.

HARDY, K, BUCKLEY S \& HUFFMAN MA. Neanderthal self-medication in context. Antiquity. 2013; 87: 873-78.

HARDY K, BUCKLEY S \& HUFFMAN MA. Doctors, chefs or hominin animals? Non-edible plants and Neanderthals. Antiquity. 2016; 90 (353): 1373-1379. doi: https://doi.org/10.15184/aqy.2016.13

HARRISON GP. Tabernanthe iboga: an African narcotic plant of social importance. Economic Botany. 1968; 23: 174-184.

HUFFMAN MA. The C.H.I.M.P.P. Group: A multi-disciplinary investigation into the use of medicinal plants by chimpanzees. Pan Africa News. 1994; 1(1): 3-5.
HUFFMAN MA. Current evidence for selfmedication in primates: a multidisciplinary perspective. Yearbook of Physical Anthropology. 1997; 40: 171-200.

HUFFMAN MA. Animal origins of herbal medicine. In From the Sources of Knowledge to the Medicines of the Future, eds. J. Fleurentin, J-M. Pelt and G. Mazars. Paris: IRD Editions, 2002; 31-42.

HUFFMAN MA. Self-medication. pp. 959-961, In: The Encyclopedia of Animal Behavior Volume 3. (Ed.) M. Bekoff, Greenwood Publishers, Westport CT. 2004.

HUFFMAN MA. Animals as a source of medicinal wisdom in indigenous societies. In: Encyclopedia of Human-Animal Relationships. Bekoff M (ed.), Connecticut: Greenwood Publishing Group. 2007a; 2: 434-441.

HUFFMAN MA. Primate self-medication. In: Primates in Perspective, eds. C. Campbell, A. Fuentes, K. MacKinnon, M. Panger and S. Bearder, Oxford: University of Oxford Press. 2007b; 677-90.

HUFFMAN MA. Chimpanzee self-medication: a historical perspective of the key findings. In: Mahale Chimpanzees- 50 years of research. (eds.) M Nakamura, K Hosaka, N Itoh, K Zamma, Cambridge University Press, Cambridge. 2015; 340-353.

HUFFMAN MA. An ape's perspective on the origins of medicinal plant use in humans. In: Hardy, K. Kubiak Martens L. (Editors), Wild Harvest. Plants in the hominin and pre-agrarian human worlds. Oxbow Books, Oxford. 2016; Chapter 3, 55-70.

HUFFMAN MA \& CATON J M. Self-induced increase of gut motility and the control of parasitic infections in wild chimpanzees. International Journal of Primatology. 2001; 22(3): 329-46. 
HUFFMAN MA, KOSHIMIZU K \& OHIGASHI H. Ethnobotany and zoopharmacognosy of Vernonia amygdalina, a medicinal plant used by humans and chimpanzees. In: Compositae: Biology \& Utilization eds. P. D. S. Caligari and D. J. N. Hind. Kew: The Royal Botanical Gardens. 1996; 2: $351-60$.

HUFFMAN MA, GOTOH S, IZUTSU D, KOSHIMIZU K \& KALUNDE MS. Further observations on the use of Vernonia amygdalina by a wild chimpanzee, its possible effect on parasite load, and its phytochemistry. African Study Monographs. 1993; 14(4): 227-40.

HUFFMAN MA \& HIRATA S. An experimental study of leaf swallowing in captive chimpanzees- insights into the origin of a selfmedicative behavior and the role of social learning. Primates. 2004; 45(2): 113-118.

HUFFMAN MA, OHIGASHI H, KAWANAKA M, PAGE JE, KIRBY GC, GASQUET M, MURAKAMI A, \& KOSHIMIZU K. African great ape selfmedication: A new paradigm for treating parasite disease with natural medicines? In: Towards Natural Medicine Research in the 21st Century, (Ed.) Y. Ebizuka, Amsterdam: Elsevier Science B.V. 1998; 113-123.

HUFFMAN MA \& SEIFU M. Observations on the illness and consumption of a possibly medicinal plant Vernonia amygdalina (Del.), by a wild chimpanzee in the Mahale Mountains National Park, Tanzania. Primates. 1989; 30(1): 51-63.

HUFFMAN MA, SPIEZIO C, SGARAVATTI A \& LECA J-B. Option biased learning involved in the acquisition and transmission of leaf swallowing behavior in chimpanzees (Pan troglodytes)? Animal Cognition. 2010; 13 (6): 871-880.

JOHNS T. With Bitter Herbs They Shall Eat It. Tucson: The University of Arizona Press. 1990.
KRIEF S, HLADIK C \&, HAXAIRE C. Ethnomedicinal and bioactive properties of the plants ingested by wild chimpanzees in Uganda. Journal of Ethnopharmacology. 2005; 101: 115.

KRIEF S, HUFFMAN MA, SÉVENET T, GUILLOT J, HLADIK C-M, GRELLIER P, LOISEAU M \& WRANGHAM RW. Bioactive properties of plant species ingested by chimpanzees (Pan troglodytes schweinfurthii) in the Kibale National Park, Uganda. American Journal of Primatology. 2006; 68: 51-71.

MACINTOSH AJJ \& HUFFMAN MA. Towards understanding the role of diet in host-parasite interactions in the case of Japanese macaques, In: The Japanese macaques (eds.) F. Nakagawa, M. Nakamichi, H. Sugiura, Springer, Tokyo. 2010; 323-344.

MUKHERJEE JR, CHELLADURAI V, RONALD J, RAWAT GS, MANI P \& HUFFMAN MA. Do animals eat what we do? Observations on medicinal plants bused by humans and animals of Mudanthurai Range, Tamil Nadu. In: Medicinal Plants and Sustainable Development ed. CP Kala, Nova Science Publications, New York. 2011; 179-195.

PETRONI LM, HUFFMAN MA \& RODRIQUEZ E. Medicinal plants in the diet of woolly spider monkeys (Brachyteles arachnoides, E. Geoffroy, 1806) a bio-rational for the search of new medicines for human use? Revista Brasileira de Farmacognosia. 2016; doi: http://dx.doi.org/10.1016/j.bjp.2016.09.002

REYNOLDS V, LLOYD AW, BABWETEERA F \& ENGLISH CJ. Decaying Raphia farinifera Palm Trees Provide a Source of Sodium for Wild Chimpanzees in the Budongo Forest, Uganda. PLoS ONE. 2009; 4(7): e6194. doi:10.1371/journal.pone.0006194

ROTHMAN JM, VAN SOEST PJ \& PELL AN. Decaying wood is a sodium source for mountain gorillas. Biology Letters. 2006; 2:321-324. 